\title{
Characteristic values of geotechnical parameters in Eurocode 7
}

Anders Prästings MSc

PhD candidate, Department of Civil and Architectural Engineering, KTH Royal Institute of Technology, Stockholm, Sweden

(corresponding author: anders.prastings@byv.kth.se) (Orcid:0000-0001-5243-4650)

\section{Johan Spross PhD}

Postdoctoral Researcher, Department of Civil and Architectural

Engineering, KTH Royal Institute of Technology, Stockholm, Sweden (Orcid:0000-0001-5372-7519)

\section{Stefan Larsson PhD}

Professor, Department of Civil and Architectural Engineering, KTH Royal Institute of Technology, Stockholm, Sweden (Orcid:0000-0001-9615-4861)

Lack of harmonisation between reliability-based design and the partial factor method in Eurocode 7 (EN 1997-1:2004) is preventing the widespread introduction of a risk-based concept in geotechnical design. This paper discusses how uncertainties are managed according to EN 1997-1:2004 and possible implications of not harmonising the current safety format with reliability-based design. One of several challenges highlighted is how EN 1997-1:2004 defines the characteristic value and design value. The characteristic value is therein defined based on a classical frequentist approach through a confidence interval. From a Bayesian point of view, the current definition does not treat the characteristic value as an uncertain variable. Consequently, the definitions of the characteristic value and design value in EN 1997-1:2004 feature weak connections between uncertainties in the geotechnical properties and the consequences of failure, as regulated by the target reliability index.

\section{Notation}

$b$

$\mathrm{COV}_{*}$

$\mathrm{COV}_{\text {inherent }}$

$\mathrm{COV}_{\text {measurement }}$

$\mathrm{COV}_{\text {statistical }}$

$\mathrm{COV}_{\text {transformation }}$

$\left.E{ }^{*}\right]$

$n$

$p_{\mathrm{f}}$

$R$

$R_{\mathrm{d}}$

$R_{\mathrm{k}}$

$S$

$S_{*}^{2}$

$s_{\mathrm{u}}$

$t_{n-2}^{0.95}$

X

$x$

$\bar{x}$

$\boldsymbol{x}$

$x_{\mathrm{c}}$

$x_{\text {chosen }}$

$x_{\mathrm{d}} x_{\mathrm{d}}^{\mathrm{EC7}\}}$

$x_{\mathrm{d}}$ SNA

$x_{\mathrm{k}}^{\{\mathrm{EC} 7\}}$ regression parameter (slope)

coefficient of variation of *

inherent variability

measurement error

statistical uncertainty

transformation uncertainty

expected value of *

number of measurements

probability of failure

resistance parameter

design value of resistance

characteristic value of resistance

load parameter

sample variance of *

undrained shear strength

Student- $t$ statistical coefficient for

95\% confidence

ground strength property

point value of $X$

mean value of $X$

vector representing values derived from

laboratory and field measurements

characteristic value of $X$

$\bar{x}$ or a subjectively estimated mean as allowed by the Swedish national annex to Eurocode 7

(SNA-Eurocode 7)

design value of $X$

$x_{\mathrm{d}}$ in accordance with Eurocode 7

$x_{\mathrm{d}}$ in accordance with SNA-Eurocode 7

$x_{\mathrm{k}}$ in accordance with EN 1997-1:2004

(Eurocode 7)

$x_{\mathrm{k}}^{\{\mathrm{SNA}\}}$
$z$
$\alpha$
$\beta$
$\beta_{\mathrm{T}}$
$\Gamma$
$\gamma_{\mathrm{M}}$
$\gamma_{\mathrm{R}}$
$\eta$
$\eta_{i}$
$\Phi$

\author{
$x_{\mathrm{k}}$ in accordance with SNA-Eurocode 7 \\ elevation \\ sensitivity factor \\ reliability index \\ target reliability index \\ variance reduction factor \\ partial factor (as defined in Eurocode 7) \\ partial factor for resistance \\ conversion factor \\ pre-defined value related to factor $i$ \\ in SNA-Eurocode 7 \\ standardised normal distribution function
}

\section{Introduction}

Reliability-based design has been around for quite some time, as an eligible alternative to the partial factor method. The partial factor method is the normative design approach in Eurocode 7 (EN 1997-1:2004; CEN, 2004), although many proclaim the possible benefits of using reliability-based design in geotechnical applications (Bjureland et al., 2017a, 2017b; De Koker and Day, 2018; Duncan, 2000; Fenton et al., 2016; Lo and Li, 2007; Phoon, 2017a; Phoon and Ching, 2013; Spross and Johansson, 2017; Vardanega and Bolton, 2016, among others). Nonetheless, reliability-based design needs to realistically manage the peculiarities of geotechnical design, both from an engineer's perspective and from the perspective of the soil's variable nature. To date, there are still difficulties in implementing reliability methods in engineering practice.

Some of these difficulties originate from the lack of harmonisation between reliability-based design and the definition of the partial factor method in EN 1997-1:2004 (CEN, 2004). 
Notably, the partial factor method was introduced to bridge the gap between the prevailing factor of safety format and reliability-based design; as such, the partial factor method is fundamentally a semi-probabilistic design approach in which partial factors are calibrated such that a uniform reliability level is achieved across different design scenarios (Phoon and Retief, 2015). In the Eurocode, partial factors should be calibrated such that the reliability levels for representative structures are as close as possible to the target reliability level. The definition in EN 1997-1:2004 (CEN, 2004), however, stipulates fixed partial factors in the national annexes, which may limit the opportunity to account for large variations in uncertainties in geotechnical design (Bjureland et al., 2017a; Phoon, 2017a; Prästings et al., 2017). Notably, partial factors may be applied to either resistance factors or geotechnical strength parameters; the latter procedure will be at the centre of the discussion in this paper. Regarding geotechnical strength parameters, EN 1997-1:2004 (CEN, 2004) accounts for varying uncertainties through the implementation of cautiously selected characteristic values, which may be determined subjectively or statistically in relation to the $5 \%$ fractile. It is argued that the statistical definition (i.e. the $5 \%$ fractile) of the characteristic value, in combination with a fixed partial factor, may limit the possibility to account stringently for varying uncertainties and to achieve a uniform reliability level in geotechnical design.

In both semi-probabilistic design and fully probabilistic reliability-based design, that is level II and III (EN 1990:2002; CEN, 2002), the most difficult issues typically arise during the process of establishing a probabilistic description of uncertain variables. In the design of geotechnical engineering structures, the number of uncertain variables is often reduced to include strength parameters such as the internal friction angle, cohesion or undrained shear strength, whereas load parameters are seldom considered stochastic. According to the authors' experience, the most common argument for simply ignoring employing probabilistic descriptions of geotechnical properties, in other words, abandoning reliability-based design, seems to be related to a general lack of data. Notably, the geotechnical property data obtained during site investigations are often too sparse to generate meaningful statistics (Forrest and Orr, 2010; Orr and Breysse, 2008; Wang, 2017); Phoon (2017b) calls this the 'curse of small sample size'.

This paper discusses how uncertainties in geotechnical properties are managed according to EN 1997-1:2004 (CEN, 2004) and the possible implications of not harmonising the current safety format with reliability-based design. It introduces the definition of the partial factor method in EN 1997-1:2004 (CEN, 2004), followed by a review of the uncertainties that are accounted for in the statistical definition of the characteristic value (i.e. the $5 \%$ fractile). On this basis, it is discussed (a) whether the $5 \%$ fractile is suitable to use to account for varying geotechnical uncertainties in the partial factor method, (b) whether the curse of small sample size is a valid argument to dismiss estimation of geotechnical property statistics and $(c)$ how to bridge the gap between design with partial factors in future versions of the Eurocode and reliability-based design.

\section{The partial factor method}

The main variabilities and errors affecting geotechnical design are presented in Figure 1 (Ang and Tang, 2007; Baecher and Christian, 2003; Vanmarcke, 1977, among many others). Managing the risk and uncertainty caused partly by these variabilities and errors while obtaining an acceptable level of reliability for representative structures is the objective of the geotechnical design. This is also the objective of the partial factor method in EN 1997-1:2004 (CEN, 2004), or any other risk-based design methodology for that matter. As such, EN 1997-1:2004 (CEN, 2004) aims to achieve a target reliability level by using design values that are obtained by applying partial factors to characteristic values of resistance $(R)$ and loads $(S)$. Figure 2 illustrates the general example of obtaining design values of resistance $\left(R_{\mathrm{d}}\right)$ by dividing characteristic values $\left(R_{\mathrm{k}}\right)$ with a partial factor $\left(\gamma_{\mathrm{R}}\right)$. The reliability index $(\beta)$ is a measure of the probability of failure by way of $p_{\mathrm{f}}=\Phi(-\beta)$, where $\Phi$ is the standardised normal distribution function. The $\gamma_{\mathrm{R}}$ factor is calibrated against a predefined reliability level through its corresponding target reliability index $\left(\beta_{\mathrm{T}}\right)$ (e.g. Melchers and Beck, 2018; Thoft-Christensen and Baker, 1982). For resistance $R\left(X_{1}, X_{2}, \ldots, X_{n}\right)$, the design values of geotechnical parameters are defined in EN 1997-1:2004 (CEN, 2004) by

$$
\text { 1. } x_{\mathrm{d}}^{\{\mathrm{EC} 7\}}=\frac{x_{\mathrm{k}}^{\{\mathrm{EC} 7\}}}{\gamma_{\mathrm{M}}}
$$

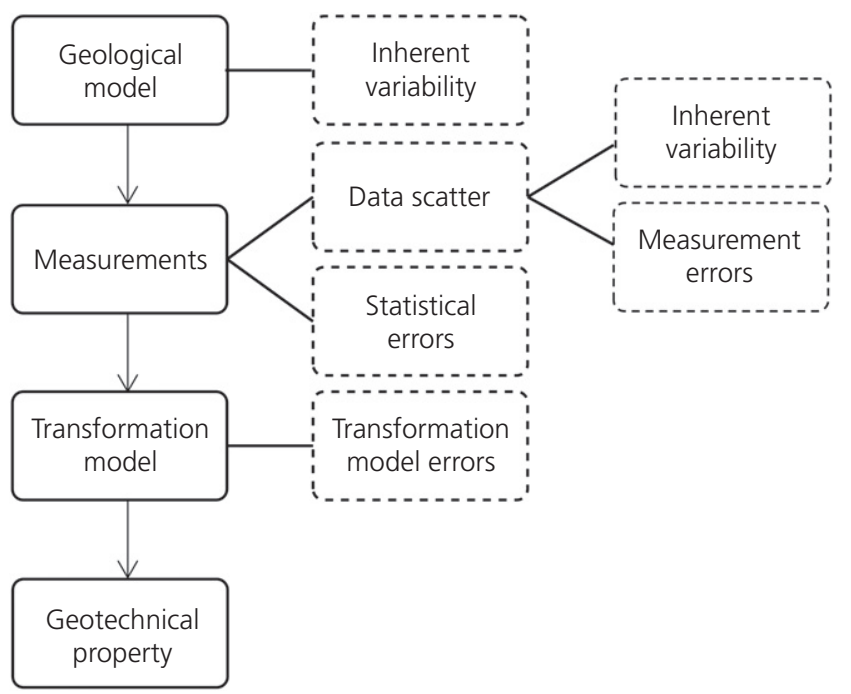

Figure 1. Categorisation of geotechnical variabilities and errors, modified based on Spross (2016) 


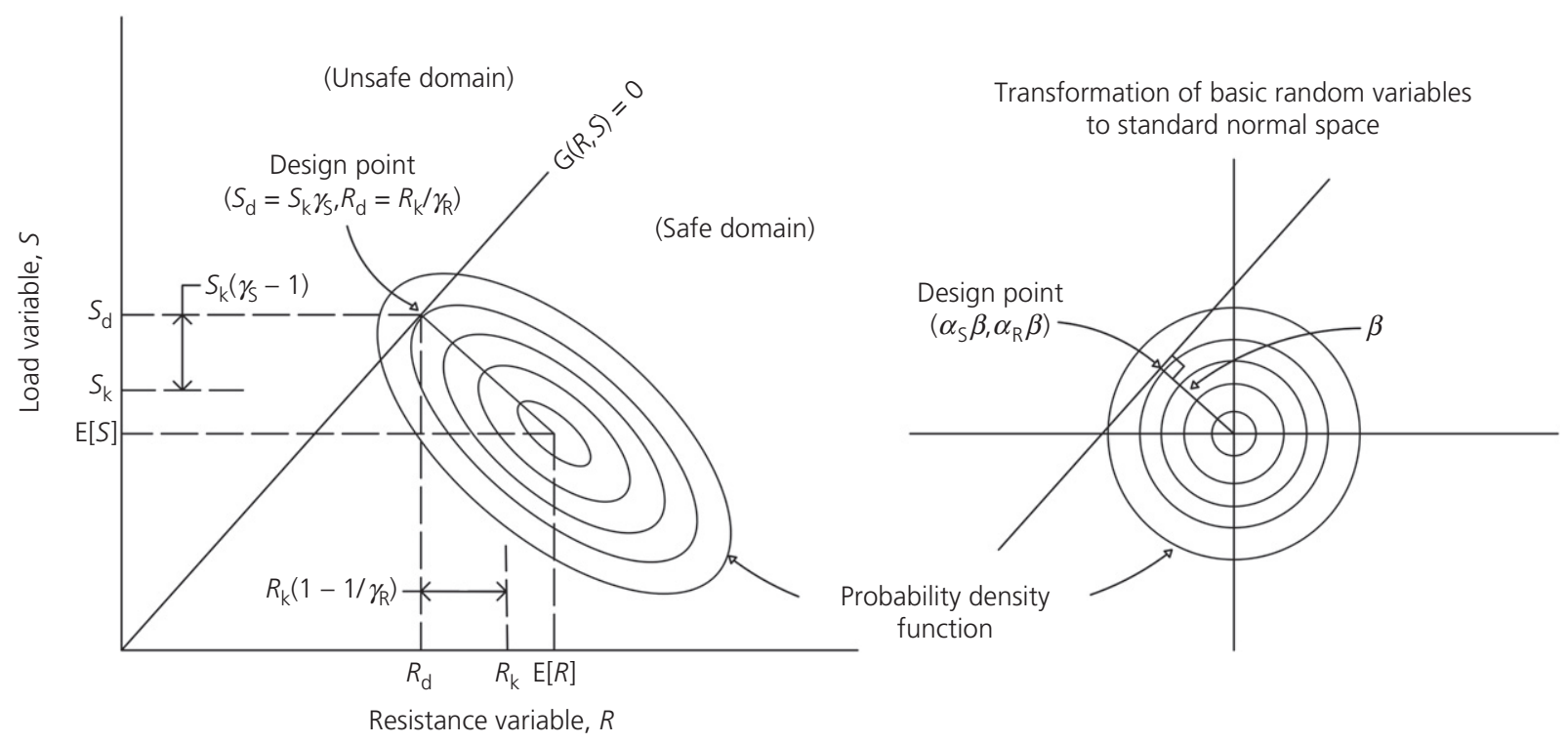

Figure 2. Relationship between mean value, characteristic value and design value

where $x_{\mathrm{k}}^{\{\mathrm{EC} 7\}}$ is the characteristic value and $\gamma_{\mathrm{M}}$ is the partial factor for the specific geotechnical parameter, also accounting for model uncertainties and dimensional variations. Notably, this paper focuses on the uncertainties related to geotechnical parameters, although dimensional variations from the specified ground model may be more influential than any variation in the geotechnical parameter.

According to Frank et al. (2004), the partial factors and the uncertainties that they cover are further described in EN 1990:2002 (CEN, 2002) (in Section 6 and Annex C9). Therein, the relationship between individual partial factors is given by $\gamma_{\mathrm{M}}=\gamma_{\mathrm{Rd}} \times \gamma_{\mathrm{m}}$, where $\gamma_{\mathrm{Rd}}$ and $\gamma_{\mathrm{m}}$ are the partial factors for uncertainty in the structural resistance model and for the material or product property, respectively. According to EN 1990:2002 (CEN, 2002), the latter factor shall account for 'the possibility of an unfavourable deviation of a material or product property from its characteristic value', and the informative Figure C3 in EN 1990:2002 (CEN, 2002) states that $\gamma_{\mathrm{m}}$ should consider the uncertainty in material properties. The transformation to standard normal space (Figure 2) relates the design points in the non-normal space to the standard normal space. Based on this transformation, the partial factor $\gamma_{\mathrm{m}}$ for any geotechnical parameter - for example, the friction angle or shear strength - may be expressed in general terms, assuming normal and lognormal distributions, respectively (e.g. Melchers and Beck, 2018; Thoft-Christensen and Baker, 1982)

2. $\gamma_{\mathrm{m}}=\frac{x_{\mathrm{k}}}{x_{\mathrm{d}}}=\frac{x_{\mathrm{k}}}{\bar{x} \times\left(1-\alpha \times \beta_{\mathrm{T}} \times \mathrm{COV}\right)}$
3. $\gamma_{\mathrm{m}}=\frac{x_{\mathrm{k}}}{x_{\mathrm{d}}}=\frac{x_{\mathrm{k}}}{\bar{x} \times \mathrm{e}^{-\alpha \times \beta_{\mathrm{T}} \times \mathrm{COV}}}$

where $\bar{x}$ is the mean value, $x_{\mathrm{k}}$ is the characteristic value as defined by the code; $\alpha$ is the FORM (first-order reliability method) sensitivity factor; and COV represents the variability in the material or product property that the code developer regards as appropriate to provide the required level of safety for the typical design situation. In EN 1997-1:2004 (CEN, 2004), the uncertainty that is considered in $\gamma_{M}$ (through $\gamma_{\mathrm{m}}$ ) is not a matter for the practising geotechnical engineer to decide upon, but is rather a matter addressed by the code writer within each national standards body. Notably, EN 1997-1:2004 (CEN, 2004) therefore stipulates a fixed $\gamma_{M}$, where the calibration of $\gamma_{M}$ is performed in the making of the national annex. Nevertheless, the selection of $\gamma_{M}$ for a specific geotechnical parameter should consider the typical variability of the parameter within the domains of each Eurocode member country, due to diverse geological conditions, design situations and local practise (Phoon and Ching, 2013). However, the fact that $\gamma_{M}$ is fixed is, according to Phoon and Ching (2013), a subject for concern because a single partial factor is unlikely to provide a uniform reliability level if the range of variability for the specific geotechnical parameter is too large.

Thus, to approach the objective of achieving an acceptable level of reliability across different design scenarios, the design framework must be able to manage the uncertainties in the geotechnical parameters that have been obtained from engineering judgement, empirical correlations and geotechnical investigations. In EN 1997-1:2004 (CEN, 2004), the uncertainties in 
geotechnical parameters are therefore managed through the selection of $x_{\mathrm{k}}^{\{\mathrm{EC} 7\}}$. The $x_{\mathrm{k}}^{\{\mathrm{EC} 7\}}$ of some material design property, $X$ (with point values $x$ ), is defined in EN 1997-1:2004, clause 2.4.5.2 (CEN, 2004), as

(2)P The characteristic value of a geotechnical parameter shall be selected as a cautious estimate of the value affecting the occurrence of the limit state.

or

(11) If statistical methods are used, the characteristic value should be derived such that the calculated probability of a worse value governing the occurrence of the limit state under consideration is not greater than $5 \%$.

Presupposing the statistical definition of the characteristic value in EN 1997-1:2004 (CEN, 2004) provides the means to discuss whether the $5 \%$ fractile is suitable to use to account for varying geotechnical uncertainties in the partial factor method. In the following section, the way uncertainties propagate through the derivation of the $5 \%$ fractile is investigated.

\section{Characteristic values of geotechnical parameters according to Eurocode 7}

3.1 Uncertainties accounted for by the $5 \%$ fractile

Any fractile may account for uncertainties in the estimation of geotechnical properties. However, it is important to note that it is the underlying probability density function (PDF), from which the fractile is calculated, that contains information about the variability of $X$. But, the uncertainties that propagate into the PDF are rarely communicated on statistical grounds in the geotechnical literature. Instead, EN 1997-1:2004 (CEN, 2004), and accompanying Eurocode guides (e.g. Frank et al., 2004), refer to a list of uncertainties and other factors (clause 2.4.5.2(4)P in EN 1997-1:2004 (CEN, 2004)) that the $x_{\mathrm{k}}^{\{\mathrm{EC} 7\}}$ shall account for. In practice, engineers need to understand the concept of selecting a value for the geotechnical parameter governing a limit state that may only be exceeded in $5 \%$ of the cases. Understanding this basic concept, the uncertainties and other factors listed in clause 2.4.5.2(4)P are to a large extent accounted for based on prior experience. However, if an engineer determines $x_{\mathrm{k}}^{\{\mathrm{EC} 7\}}$ statistically, does he or she actually account for the uncertainties and other factors listed in clause 2.4.5.2(4)P from a statistical point of view? If an engineer determines $x_{\mathrm{k}}^{\{\mathrm{EC} 7\}}$ subjectively, how can he or she ever know? Consequently, one may ask 'Do engineers understand what uncertainties are accounted for by the $5 \%$ fractile?'. Although the cautiousness provided by the $5 \%$ fractile may contribute to structural safety, this particular fractile is chosen by tradition, and to harmonise with other engineering disciplines (Wang, 2017).
From a statistical point of view, in the definition of $x_{\mathrm{k}}^{\{\mathrm{EC} 7\}}$ (clause 2.4.5.2(2)P), the phrase 'value governing the occurrence of the limit state' basically acknowledges that there are at least two design situations that must be considered in the selection of $x_{\mathrm{k}}^{\{\mathrm{EC} 7\}}$. Hence, according to clause 2.4.5.2 (CEN, 2004)

(7) The zone of ground governing the behaviour of a geotechnical structure at a limit state is usually much larger than a test sample or the zone of ground affected in an in situ test. Consequently the value of the governing parameter is often the mean of a range of values covering a large surface or volume of the ground.

The characteristic value should be a cautious estimate of this mean value.

and

(8) If the behaviour of the geotechnical structure at the limit state considered is governed by the lowest or highest value of the ground property, the characteristic value should be a cautious estimate of the lowest or highest value occurring in the zone governing the behaviour.

In the latter case (8) (which corresponds to a local failure, in which a small volume of soil is governing the occurrence of the limit state), the $x_{\mathrm{k}}^{\{\mathrm{EC} 7\}}$ shall be selected as the $5 \%$ fractile of the PDF representing the variability in $X$. In the former case (7) (which corresponds to a non-local failure, in which the limit state is governed by a large volume of soil), the $x_{\mathrm{k}}^{\{\mathrm{EC} 7\}}$ shall instead be selected with $95 \%$ confidence in the mean value, $\bar{x}$, evaluated from the sample values $x$ (note that this definition is also consistent with the $5 \%$ fractile of the PDF of $\bar{x}$ ). In contrast, to the design situation in (8), the situation given by (7) presumes that a mean value may be estimated from investigations located within the relevant soil volume (Frank et al., 2004). A graphical representation of $x_{\mathrm{k}}^{\{\mathrm{EC} 7\}}$ is presented in Figure 3. It should be noted that a geotechnical parameter is basically a simplification of a complex non-linear dependence of stresses and strains. Additionally, some limit states are governed not by mean values but rather by the difference between them, which is the case for some serviceability limit states. Thus, apart from the guidance given in (7) and (8), the phrase 'value governing the occurrence of the limit state' presumes that the practising engineer understands the geotechnical parameter's role in the specific limit state. Notably, the required level of knowledge of the geotechnical engineer is managed in EN 1997-1:2004 (CEN, 2004) by the assumptions in 1.3(2), which state that 'data required for design are collected, recorded and interpreted by appropriately qualified personnel'.

\subsection{Uncertainties that propagates through} the derivation of the $5 \%$ fractile

If a failure develops within a small volume of soil, the failure may - with an increased probability - occur mainly within 


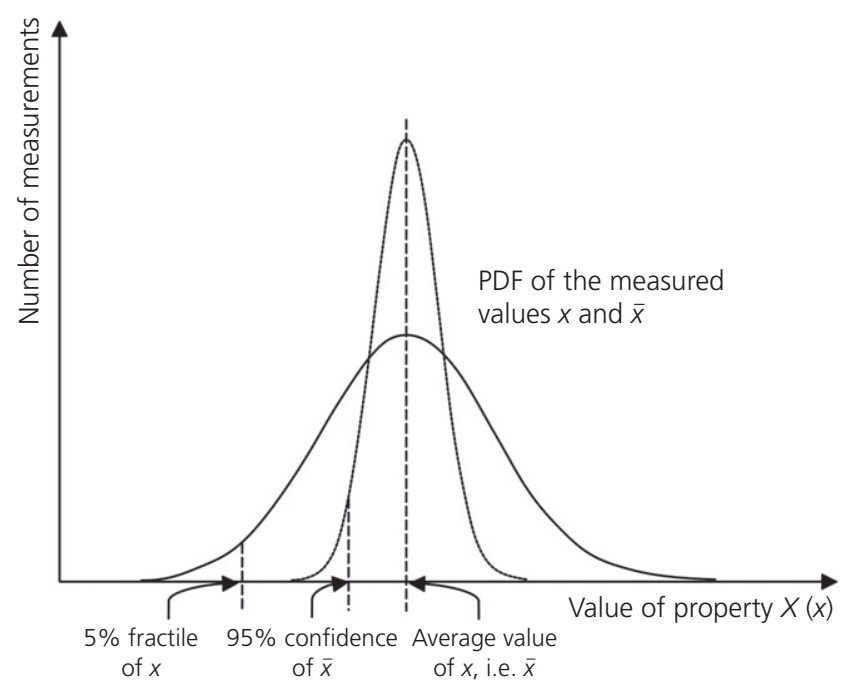

Figure 3. Uncertainties accounted for in $x_{c}^{\{E C 7\}}$, modified based on Prästings et al. (2017)

locally weak soil. In contrast, if a failure develops within a large volume of soil, the failure may occur within both locally weak and strong soil. As such, the decision of whether a failure may be considered as small or large is highly related to the soil's autocorrelation structure - that is, the scale of fluctuation (Frank et al., 2004). The distinction between small (local) and large (non-local) failure basically means that the contribution from inherent variability diminishes on account of spatial averaging (Fenton and Griffiths, 2008; Vanmarcke, 2010). These design situations may therefore represent the extremes regarding the contribution from inherent variability in a design: one in which no reduction of the uncertainty related to inherent variability is performed because of the small spatial extent of the governing failure influencing the zone in comparison to the scale of fluctuations and the other extreme, in which complete reduction of the uncertainty related to inherent variability is performed.

Using the notation of coefficient of variation (COV), the total uncertainty in geotechnical properties (Figure 1) may be (simplified from Müller et al., 2014)

4.

$$
\begin{aligned}
\mathrm{COV}_{\text {total }}^{2} \approx & \Gamma^{2} \times \mathrm{COV}_{\text {inherent }}^{2}+\mathrm{COV}_{\text {measurement }}^{2} \\
& +\mathrm{COV}_{\text {transformation }}^{2}+\mathrm{COV}_{\text {statistical }}^{2}
\end{aligned}
$$

where the COVs represent the uncertainty related to inherent variability, random measurement error, transformation error and statistical error and $\Gamma$ is a variance reduction factor (see e.g. Vanmarcke, 1977, 2010). In the cases of the two extremes, $\Gamma=1$ for local failure and $\Gamma=0$ for non-local failure.

To highlight which uncertainties propagate into the PDF, from which the $5 \%$ fractile is calculated, the guidance in Frank et al. (2004) is followed to calculate $x_{\mathrm{k}}^{\{\mathrm{EC} 7\}}$ for a uniform soil with a linear trend in the direction of depth, with the expected value $E(X \mid z)$. Therein, the $x_{\mathrm{k}}^{\{\mathrm{EC} 7\}}$ values are determined based on the variability of $X$, which is represented by the sample variance

5. $s_{X}^{2}=\frac{\sum_{i=1}^{n}\left[\left(x_{i}-\bar{x}\right)-b \sum_{i=1}^{n}\left(z_{i}-\bar{z}\right)\right]^{2}}{n-2}$

where $n$ is the number of measurements; $b$ is the slope of the regression line; and $\bar{z}$ can be interpreted as the centre of gravity of the measurements, $\boldsymbol{x}=\left[x_{1}, x_{2}, \ldots, x_{n}\right]$, at a depth of $z_{i}$. Notably, the vector $\boldsymbol{x}$ represents values that have been derived (i.e. transformed) from laboratory and field measurements. This means that bias due to transformation uncertainty affects the value of $\bar{x}$. However, only random uncertainties are visible in the variability of $X$ and the systematic uncertainties are therefore not accounted for in $s_{X}^{2}$ (Zhang et al., 2004). $s_{X}^{2}$ may be written in terms of a COV of $X, \operatorname{COV}_{X}$. Since $\boldsymbol{x}$ only reflects the outcome of the measurements, $\mathrm{COV}_{X}$ accounts for the uncertainty related to inherent variability and measurement error according to

6. $\mathrm{COV}_{X}^{2} \approx \mathrm{COV}_{\text {inherent }}^{2}+\mathrm{COV}_{\text {measurement }}^{2}$

In case of a potential local failure $(\Gamma=1)$, Frank et al. (2004) calculate the variance in $X$, at a depth $z$, based on a standard frequentist approach to statistical inference

7. $s_{X \mid z}^{2}=s_{X}^{2}+(\underbrace{\frac{1}{n}+\frac{(z-\bar{z})^{2}}{\sum_{i=1}^{n}\left(z_{i}-\bar{z}\right)^{2}}}_{\text {Leverage }}) s_{X}^{2}$

where the contents within the brackets are referred to as the leverage about the centre of gravity of $\boldsymbol{x}$ (Wakefield, 2013). The product of the leverage and $s_{X}^{2}$ in Equation 7 can be interpreted as the uncertainty in the trend $E(X \mid z)$, which is similar to the statistical uncertainty $\mathrm{COV}_{\text {statistical }}$ as defined in Müller et al. (2014, 2016). However, Müller et al. use a Bayesian approach to statistical inference and include a term to account for the uncertainty in the estimate of $s_{X}^{2}$, as per the example of Tang (1980). Thus, for the local failure $(\Gamma=1)$, the variance in $X$ (Equation 7) is thereby consistent with the total uncertainty in terms of the COV according to

8.

$$
\begin{gathered}
\mathrm{COV}_{\text {total }}^{2}(X \mid z) \approx \mathrm{COV}_{\text {inherent }}^{2}+\mathrm{COV}_{\text {measurement }}^{2} \\
+\mathrm{COV}_{\text {statistical }}^{2}=\mathrm{COV}_{X}^{2}+\mathrm{COV}_{\text {statistical }}^{2}
\end{gathered}
$$

where $\mathrm{COV}_{\text {statistical }}$ represents the product of the leverage and $s_{X}^{2}$ in Equation 7. 
In case of a potential non-local failure $(\Gamma=0)$, Frank et al. (2004) calculate the variance in $\bar{x}$, at a depth $z$, using

9. $s_{\bar{x} \mid z}^{2}=(\underbrace{\frac{1}{n}+\frac{(z-\bar{z})^{2}}{\sum_{i=1}^{n}\left(z_{i}-\bar{z}\right)^{2}}}_{\text {Leverage }}) s_{X}^{2}$

The fact that $\Gamma=0$ for the non-local failure eliminates the uncertainty related to inherent variability in Equation 4. However, because EN 1997-1:2004 (CEN, 2004) lumps together the uncertainty related to inherent variability and measurement error in $\operatorname{COV}_{X}$ (Equation 6) - that is, they are not treated separately - the measurement error will be indirectly affected by the constraint that $\Gamma=0$. Notably, this constraint corresponds to the lost $s_{X}^{2}$ in Equation 9 compared to Equation 7 and, consequently, the variance in $\bar{x}$ is thereby consistent with the total uncertainty in terms of the $\mathrm{COV}$ according to

$$
\text { 10. } \mathrm{COV}_{\text {total }}^{2}(\bar{x} \mid z)=\mathrm{COV}_{\text {statistical }}^{2}
$$

$x_{\mathrm{k}}^{\{\mathrm{EC} 7\}}$ may then be calculated on the assumption of $X$ following a Student's $t$ distribution with $(n-2)$ degrees of freedom, for the local failure and non-local failure, respectively

$$
\text { 11a. } x_{\mathrm{k}}^{\{\mathrm{EC} 7\}}(X \mid z)=[\bar{x}+b(z-\bar{z})]-t_{n-2}^{0.95} \times s_{X \mid z}
$$

11b. $\quad x_{\mathrm{k}}^{\{\mathrm{EC} 7\}}(\bar{x} \mid z)=[\bar{x}+b(z-\bar{z})]-t_{n-2}^{0.95} \times s_{\bar{x} \mid z}$

where $t_{n-2}^{0.95}$ is a statistical coefficient that depends on the number of test results $(n)$ and the level of confidence required for the determination of $x_{\mathrm{k}}^{\{\mathrm{EC} 7\}} \cdot t_{n-2}^{0.95}$ also includes some consideration of the statistical model error, which is related to the assumption of distribution type.

Through the derivation of Equation $8, x_{\mathrm{k}}^{\{\mathrm{EC} 7\}}(X \mid z)$ for the local failure $(\Gamma=1)$ accounts for uncertainty related to inherent variability, measurement error and statistical error by way of $s_{X \mid z}$. Furthermore, through derivation of Equation 10, $x_{\mathrm{k}}^{\{\mathrm{EC} 7\}}(\bar{x} \mid z)$ accounts for statistical uncertainty solely by way of $s_{\bar{x} \mid z}$. Although it is possible to identify which uncertainties are accounted for in $x_{\mathrm{k}}^{\{\mathrm{EC} 7\}}$ by way of $s_{X \mid z}$ and $s_{\bar{x} \mid z}$ (Equations 11a and 11b), the contribution from the selection of $t_{n-2}^{0.95}$ - that is, the degree of confidence or fractile for which $x_{\mathrm{k}}^{\{\mathrm{EC} 7\}}$ is calculated - remains unclear. To conclude, it is argued that the $5 \%$ fractile ineffectively accounts for varying geotechnical uncertainties in the partial factor method.

Most geotechnical problems include spatial averaging over the potential failure domain, either partially $(0<\Gamma<1)$ or fully $(\Gamma=0)$. In the latter case, the statistical uncertainty is the only uncertainty accounted for in $x_{\mathrm{k}}^{\{\mathrm{EC} 7\}}$ by way of $s_{\bar{x} \mid z}$ (Equation 10). This implies that the uncertainty accounted for in $x_{\mathrm{k}}^{\{\mathrm{EC} 7\}}(\bar{x} \mid z)$ (Equation 11b) approaches zero only if a sufficient number of measurements are performed. For the opposite case - that is, when the measurements are few engineers must address the so-called curse of small sample size in the estimation of geotechnical property statistics (Phoon, 2017b). Because small samples of data are common in geotechnical engineering, Orr (2000), Orr and Breysse (2008) and Pohl (2011) infer that the use of statistics may be less applicable in geotechnical engineering than, for example, in structural engineering. In the following section, the question of whether a small sample size is a problem is investigated.

\section{Small sample size issues}

In the Bayesian approach to statistical inference, probabilities can be used to represent the uncertainty in geotechnical parameters. The Bayesian definition of probability is typically referred to as the degree-of-belief approach, which means that probabilities represent one's confidence in an outcome. Conversely, the frequentist definition of probability of an outcome is its relative frequency of occurrence; thus, the definition concerns the characterisation of the variability in measured data or observed occurrences (Vick, 2002). Furthermore, the Bayesian approach allows for prior information in the form of expert knowledge (i.e. subjective reasoning) to be updated as additional information becomes available. From a Bayesian point of view, it makes sense to perform reliability-based design (of both level II and III), even in the case in which only small samples of data are available. As will be discussed in this section, the existence of the curse of small sample size is not clear, especially in Bayesian inference.

In geotechnical engineering, the small sample size introduces a problem in the frequentist approach to statistical inference. A frequentist might feel comfortable in producing statistical estimates based on repeatable events and when the uncertainty is due to randomness (Wagenmakers et al., 2008). However, in the absence of a significant number of measurements and when the uncertainty is also due to lack of knowledge (as in geotechnical engineering), the frequentist might propose that statistical estimates are impracticable. To sidestep this problem, Bayesian methodologies are widely proposed for statistical inference based on small samples of geotechnical data (Cao and Wang, 2014; Cao et al., 2016; Wang and Xu, 2015; Yang et al., 2017, among others). However, there seem to be difficulties in implementing Bayesian methodologies in the existing code documents, difficulties that may be related to the lack of harmonisation between deterministic design methodologies and reliability-based design. As such, could the lack of harmonisation between the partial factor method in EN 1997-1:2004 (CEN, 2004) and reliability-based design 
originate from the dispute between the frequentist and Bayesian approach to statistics?

Vick (2002) tells a story from a meeting about risk analysis. When the discussion at the meeting advanced into the area of reliability-based design, it became clear that the participants at the meeting based their perceptions on how to characterise geotechnical properties statistically on different probability connotations, one as the objective frequency and the other as a degree of belief. Consider the excerpt from Vick (2002: p. vii (preface))

The discussion started out well enough; that is, until turning to the heart of the matter - probabilistic methods. Some thought it best to find analytical models that everyone could agree on, then add statistical overlays to the input data. Others were concerned with the kinds of uncertainties that can't be analysed - just characterised, using judgement. Gradually it became clear there was a language problem far beyond those being spoken: a shared language of probability was simply not there.

Whether to adopt one or other of these approaches in geotechnical engineering has not been sufficiently discussed in the geotechnical community. This leads to a general confusion about the difference between these views. In the following paragraph, the pros and cons of the Bayesian and frequentist approaches in geotechnical engineering are highlighted, considering the common lack of knowledge because of too few measurements.

Since geotechnical design typically commences with a general lack of knowledge or evidence (data) about the geotechnical conditions, some measure is required to reduce this lack of knowledge to obtain a manageable level of uncertainty. In other words, a sufficient number of samples (i.e. geotechnical in situ and laboratory measurements) is indeed required to obtain a reliable $x_{\mathrm{k}}^{\{\mathrm{EC} 7\}}$ (Honjo and Setiawan, 2007). As such, how to perform sufficient geotechnical site investigations has been a question for years: both Honjo et al. (2006) and Lumb (1974) employ a classical frequentist approach to determine the required sample size through confidence intervals. The frequentist approach is also used in Eurocode 7, in which $x_{\mathrm{k}}^{\{\mathrm{EC} 7\}}$ is calculated based on an interval that contains the actual value with $95 \%$ confidence (i.e. the confidence interval), or the $5 \%$ fractile. From a frequentist point of view, $x_{\mathrm{k}}^{\{\mathrm{EC} 7\}}$ is considered temporally stochastic. That is, when measurements are added in a later stage in the design process, $x_{\mathrm{k}}^{\{\mathrm{EC} 7\}}$ may be revised, although at any given time, there is only one true value of $x_{\mathrm{k}}^{\{\mathrm{EC} 7\}}$ and no uncertainty. Notably, the frequentist interpretation may judge whether a value $x$ is statistically significant based on the analysis of conducted measurements. However, to do so, a sufficient number of samples would indeed be required to analyse the variability of $X$ and to determine $x_{\mathrm{k}}^{\{\mathrm{EC} 7\}}$ and subsequently $x_{\mathrm{d}}^{\{\mathrm{EC} 7\}}$ through Equation 1. In contrast, the Bayesian approach allows for the lack of knowledge in the analysis of $X$ (prior uncertainty) to yield a prediction of the posterior uncertainty at any given time in the design process. As such, given a small sample size the posterior estimate of the statistical uncertainty will be high, as will the total uncertainty (Equation 4). As an effect, the resulting design will likely be conservative (overly expensive), compared to a situation with a larger sample size.

If there is a large lack of knowledge about $X$, for example in the case of a small sample size, the geotechnical engineer may face one of the following scenarios depending on his/her statistical view.

(a) The frequentist engineers believe that $x_{\mathrm{k}}^{\{\mathrm{EC} 7\}}$ cannot be analysed statistically with a reasonable design outcome; therefore they choose to ignore the large statistical uncertainty by selecting a subjectively estimated $x_{\mathrm{k}}^{\{\mathrm{EC} 7\}}$ that, possibly with little caution considering the uncertainty, represents the cautious estimate of the governing value.

(b) The Bayesian engineers acknowledge the uncertainty and determine the characteristic value statistically. Because of the significant statistical uncertainty, the design turns out to be overly conservative. Seeing this, the engineers decide to reduce the uncertainty by performing additional investigations (if possible) or to manage the uncertainties during construction by using, for example, the observational method.

With these two scenarios, the selection of the characteristic value is an important part of the engineer's risk management work: the analysis of the present uncertainties is fundamental to geotechnical design, as it will affect how the related risk is treated (Spross et al., 2018a). From a risk management perspective, the engineers in scenario $(a)$ may be more prone to disregard the present lack of knowledge in the selection of the subjective estimate, to suit their perception of a reasonable design outcome, and thus the design may inadequately account for the present uncertainty and the related risk. Additionally, by leaving uncertainties invisible (unquantified), the risks identified in the design process are potentially not communicated to later project stages. However, scenario $(a)$ has nonetheless become standard practice because the effects of adopting scenario $(b)$ are observed as too cumbersome or too costly. From a Bayesian point of view, one would rather have highly uncertain - but probabilistic - estimates of the geotechnical properties than no estimates at all.

Furthermore, the geotechnical community should continue to support the introduction of Bayesian inference of small samples of geotechnical data (Cao and Wang, 2014; Cao et al., 2016; Wang and $\mathrm{Xu}, 2015$; Yang et al., 2017). This will give engineers a greater incentive for conducting a proper risk-based design, where uncertainties are managed stringently throughout the design and construction phase. To conclude, a small sample size should not be an obstacle to performing 
reliability-based design (of both level II and III), especially if the Bayesian school of thought is embraced.

\section{Bridging the gap between design with partial factors and reliability-based design}

This section briefly discusses how the partial factor method can be redefined towards a clear risk-based design concept, based on previous findings in Prästings et al. (2017). In reliability-based design, a stochastic variable is typically characterised by its PDF. However, the definition of $x_{\mathrm{k}}^{\{\mathrm{EC} 7\}}$ in EN 1997-1:2004 (CEN, 2004) (clause 2.4.5.2(2)P) focuses on the cautiousness that it is necessary to employ in relation to the mean value rather than on the variability of the mean value that is natural in reliability-based design. This difference in view leads to difficulties in harmonising the safety format of EN 1997-1:2004 (CEN, 2004) with reliability-based design. To approach a risk-based design concept, the primary attention in design must be on how to manage the lack of knowledge, either through the number of measurements or the choice of design methodology. Therefore, in the harmonisation of the current safety format with reliability-based design, it is rational to define the characteristic value as a spatial average of $X$, which can be statistically characterised by its parameter variability, $s_{X}^{2}$, or more specifically the total uncertainty, $\mathrm{COV}_{\text {total. }}$. If statistical methods are used to determine $s_{X}^{2}$ or $\mathrm{COV}_{\text {total }}$, the partial factor could potentially be adjusted to account for the uncertainty in $X$ and $\bar{x}$. If statistical methods are not used, the definition of the design value needs to harmonise with the fact that $X$ and $\bar{x}$ inherently are random variables. As a solution, the procedure presented in the Swedish national annex (SNA) to EN 1997-1:2004 (IEG, 2008a), which was previously discussed in Prästings et al. (2017), is suggested. In the SNA, the design value is defined as

12. $x_{\mathrm{d}}^{\{\mathrm{SNA}\}}=\frac{x_{\mathrm{k}}^{\{\mathrm{SNA}\}}}{\gamma_{\mathrm{M}}}=\frac{x_{\text {chosen }} \times \eta}{\gamma_{\mathrm{M}}}$

where $x_{\text {chosen }}$ is selected either as a subjectively estimated mean value or as $\bar{x}$ and $\eta$ is a conversion factor that is chosen by the geotechnical engineer from a set of listed values in the national annex (IEG, 2008a). In principle, $\eta$ indicates the influence of the uncertainties and factors listed in EN 1997-1:2004 (CEN, 2004) (Clause 2.4.5.2(4)P) on $x_{\text {chosen. }}$ The deterministic evaluation of $\eta$ is based on eight sub-factors according to Equation 13 and Table 1.

13. $\eta=\eta_{1} \times \eta_{2} \times \eta_{3} \times \eta_{4} \times \eta_{5} \times \eta_{6} \times \eta_{7} \times \eta_{8}$

The evaluated $\eta$ is typically between 0.8 and $1 \cdot 2$, and an example of how to evaluate $\eta_{3}$ for the undrained shear strength in a slope stability problem is given in Table 2. Using statistical methods, $\eta$ is related to the partial factor $\gamma_{M}$ according to (assuming log-normally distributed variables)

$$
\text { 14. } \quad \eta=\frac{\gamma_{\mathrm{M}}}{\mathrm{e}^{\alpha \times \beta_{\mathrm{T}} \times \mathrm{COV}_{\text {total }}}}
$$

Furthermore, Equation 14 is related to the design value by

15. $x_{\mathrm{d}}^{\{\mathrm{SNA}\}}=\frac{x_{\mathrm{k}}^{\{\mathrm{SNA}\}}}{\gamma_{\mathrm{M}}}=\frac{x_{\text {chosen }} \times \eta}{\gamma_{\mathrm{M}}}=\frac{x_{\text {chosen }}}{\mathrm{e}^{\alpha \times \beta_{\mathrm{T}} \times \mathrm{COV}_{\text {total }}}}$

Notably, EN 1997-1:2004 (CEN, 2004) limits the characteristic value to be located on one side of a given confidence interval; that is, for non-local failure, $x_{\mathrm{k}}^{\{\mathrm{EC} 7\}}$ will be located at the $5 \%$ cut-off point in the 0 to $50 \%$ range of the PDF representing the variability of $X$. As such, $x_{\mathrm{k}}^{\{\mathrm{EC} 7\}}$ provides a safety margin beyond what is already given by $\gamma_{\mathrm{M}}$. In contrast, the definition in the SNA allows for $\eta$ to take on a value that is less than, greater than or equal to 1.0 to adjust $x_{\mathrm{k}}^{\{\mathrm{SNA}\}}$, which implies that $x_{\mathrm{k}}^{\{\mathrm{SNA}\}}$ may also be located in the $50-100 \%$ range of the PDF representing the variability of $X$. In that case, the safety margin in $x_{\mathrm{d}}^{\{\mathrm{SNA}\}}$ is calibrated by way of $\eta$ and may be both lower or higher than what is given by $\gamma_{\mathbf{M}}$.

Furthermore, the definition of $x_{\mathrm{d}}^{\{\mathrm{SNA}\}}$ brings the design closer to the general risk concept, which implies that risk reduction can be performed either by reducing uncertainties $\left(\mathrm{COV}_{\text {total }}\right)$

Table 1. Definition of conversion factors in SNA-Eurocode 7 (IEG, 2008a)

$\begin{array}{ll}\eta_{i} & \text { Definition } \\ \eta_{1} & \text { The inherent variability of the material properties } \\ \eta_{2} & \text { Uncertainty related to the assessment of soil properties } \\ \eta_{3} & \text { The location of measurement points in relation to the structure } \\ \eta_{4} & \text { The extent of the ground zone governing the behaviour of the geotechnical structure at the limit state being considered } \\ \eta_{5} & \text { The ability of the geotechnical structure to transfer loads from weak to strong zones in the ground } \\ \eta_{6} & \text { Type of failure mechanism (i.e. ductile or brittle failure) } \\ \eta_{7} & \text { The sensitivity of the material design property on the limit state }\end{array}$


Table 2. Example from the evaluation of $\eta_{3}$ in SNA-Eurocode 7 (IEG, 2008b)

$\begin{array}{ll}\text { Influencing factors } & \boldsymbol{\eta}_{\mathbf{3}} \\ \text { One method of cone penetration test/field vane/fall cone have been used } & 0.90 \\ \text { Two to three methods have been used }- \text { large variability in the results } & 0.95 \\ \text { Two to three methods have been used }- \text { small variability in the results } & 1.00 \\ \text { Two to three methods have been used }- \text { small variability in the results and empirical relations }{ }^{\mathrm{b}} \text { confirm the results } & 1 \cdot 05 \\ \text { Direct simple shear tests or triaxial tests confirm the results from other investigations and empirical relations. } & 1 \cdot 10\end{array}$

${ }^{a}$ Obviously incorrect results shall be rejected

${ }^{\mathrm{b}}$ Refers to empirical relations between the undrained shear strength and the pre-consolidation stress evaluated from constant-rate-of-strain oedometer tests

or by reducing the expected consequences, as they are regulated through $\beta_{\mathrm{T}}$, as discussed by Spross et al. (2018b). Notably, EN 1990:2002 (CEN, 2002; Table B1) offers the possibility to differentiate the reliability through partial factors based on the given consequences class. However, EN 1990:2002 (CEN, 2002) states that this possibility is not normally utilised for partial factors on resistance $\left(\gamma_{M}\right)$. Furthermore, this risk-based distinction is not discussed in the partial factor method for persistent and transient design situations in EN 1997-1:2004 (CEN, 2004).

\section{Concluding remarks}

In this paper, it is suggested that the slow introduction of reliability-based design in geotechnical engineering may be related to the lack of harmonisation between the Bayesian concept of reliability-based design and the frequentistically defined partial factor method in EN 1997-1:2004 (CEN, 2004). Notably, Wang (2017) proposes the implementation of Bayesian concepts in Eurocode 7, so that the Bayesian approach is used to refine the PDF, from which the $5 \%$ fractile is calculated, for example in the case of small samples of data. As such, the partial factor method in EN 1997-1:2004 (CEN, 2004) does not preclude the use of the Bayesian approach to statistical inference. However, by squeezing these uncertainties into the frequentistically defined $x_{\mathrm{k}}^{\{\mathrm{EC} 7\}}$ (the $5 \%$ fractile), the potential of the Bayesian approach in linking efforts in site investigations to structural reliability is partly lost. The Bayesian approach offers a superior opportunity to manage geotechnical uncertainties stringently.

Adopting the statistical definition of the characteristic value in EN 1997-1:2004 (CEN, 2004) provides the means to discuss whether the $5 \%$ fractile is suitable to account for varying geotechnical uncertainties in the partial factor method. Following guidance given by Frank et al. (2004) on how to calculate $x_{\mathrm{k}}^{\{\mathrm{EC} 7\}}$ statistically and investigating which uncertainties that are accounted for in the PDF, the 5\% fractile is calculated. Notably, EN 1997-1:2004 (CEN, 2004) acknowledges that there are two extreme design situations, non-local and local failure. In the guidance given by Frank et al. (2004), these can be related to the cases in which $\Gamma$ is either 0 or 1 in Equation 4 , respectively. When $\Gamma=0$, no variance reduction is performed, and vice versa. As such, cases with partial variance reduction $(0<\Gamma<1)$ is not specifically managed in the statistical definition of $x_{\mathrm{k}}^{\{\mathrm{EC} 7\}}$; hence, the definition does not clearly acknowledge that there may be a design situation in between local and non-local failure. As $\Gamma$ for most design situations would fall in the range from 0 to 1 , the question of how to include variance reduction in the statistical definition of $x_{\mathrm{k}}^{\{\mathrm{EC} 7\}}$ is a subject for discussion; see, for example, Schneider and Schneider (2013) and Orr (2017). Furthermore, the uncertainties that propagate into the PDF, from which the $5 \%$ fractile is calculated, for local and non-local failure are presented in Equations 8 and 10 (in terms of $\operatorname{COV}_{\text {total }}(X \mid z)$ and $\left.\mathrm{COV}_{\text {total }}(\bar{x} \mid z)\right)$. Comparing Equations 8 and 10 with Equation $4\left(\mathrm{COV}_{\text {total }}\right)$, it can be seen that the transformation uncertainty is included in neither the representation of local failure nor that of non-local failure. Moreover, as the statistical determination of $x_{\mathrm{k}}^{\{\mathrm{EC} 7\}}$ is based on $s_{X}^{2}$ (Equation 5), $\mathrm{COV}_{\text {total }}(X \mid z)$ and $\operatorname{COV}_{\text {total }}(\bar{x} \mid z)$ include only random uncertainties. Consequently, the potential reduction of transformation uncertainty is not accounted for in the PDF. As high-quality investigations are typically characterised by small transformation uncertainty, $x_{\mathrm{k}}^{\{\mathrm{EC} 7\}}$ and $x_{\mathrm{d}}^{\{\mathrm{EC} 7\}}$ therefore lack a clear connection to the quality of geotechnical site investigations. In addition, dangerous design situations may arise because of the poor connection between $x_{\mathrm{d}}^{\{\mathrm{EC} 7\}}$, the quality of geotechnical site-investigations and $\beta_{\mathrm{T}}$. Consequently, the statistical definition of $x_{\mathrm{k}}^{\{\mathrm{EC} 7\}}$ (the $5 \%$ fractile) inadequately accounts for varying uncertainties in the partial factor method.

As previously noted, managing uncertainties continuously during the design process must never be disregarded only because the uncertainties cannot be analysed in accordance with EN 1997-1:2004. A small sample size is simply not a valid argument to dismiss estimation of geotechnical property statistics. Even in the case of a small sample size, engineers should let the high uncertainty of a design based on statistically unreliable data (i.e. few measurements) be reflected throughout the design process rather than hiding the uncertainty behind subjective estimates that are not committed to paper. The effect is clear: a geotechnical investigation is paid for either sooner as additional site investigations or later in the form of an overly expensive design caused by high statistical uncertainty, which results in a very cautious design value. In producing designs that are vitiated with large uncertainties, situations may occur when uncertainties must be managed in other stages of the design process. Therefore, it should also be 
possible to manage uncertainties through extensive monitoring in accordance with the observational method, as discussed by Spross and Johansson (2017). Notably, a small sample size is not always related to economic restraints; in many cases, producing a large number of measurements is simply not possible due to the project location - for example, in densely populated areas. However, how to manage large uncertainties stringently in early design stages, in the application of the observational method, requires further research as a basis for discussion within the geotechnical community. Possibly, this can happen within the ongoing revision of EN 1997-1:2004 (CEN, 2004), which is due in 2024 .

To harmonise the partial factor method in EN 1997-1:2004 (CEN, 2004) with reliability-based design, the characteristic value should be defined as a spatial average of $X$ and related to the uncertainties $\mathrm{COV}_{\text {total }}$ in Equation 4. The geotechnical uncertainties may then be managed in a probabilistic framework following the example of Equation 15, which has a deterministic definition that the authors believe harmonises with the probabilistic definition. From a Bayesian point of view, the 5\% fractile would then be redundant as a measure of cautiousness; instead, the characteristic value would simply be defined as a spatial average of an uncertain variable.

\section{Acknowledgements}

This study was undertaken as a part of the research project Transparent Underground Structure (Trust) and was funded by the Swedish Research Council Formas (the Swedish Research Council for Environment, Agricultural Sciences and Spatial Planning), the Swedish Transport Administration, Better Interaction in Geotechnics (BIG) and Tyréns AB. Their support is gratefully acknowledged.

\section{REFERENCES}

Ang AHS and Tang WH (2007) Probability Concepts in Engineering: Emphasis on Applications to Civil and Environmental Engineering, 2nd edn. John Wiley \& Sons, New York, NY, USA.

Baecher GB and Christian JT (2003) Reliability and Statistics in Geotechnical Engineering. John Wiley \& Sons, Chichester, UK. Bjureland W, Spross J, Johansson F, Prästings A and Larsson S (2017a) Challenges in applying fixed partial factors to rock engineering design. In Geo-Risk 2017: Reliability-Based Design and Code Development (Huang J, Fenton GA, Zhang L and Griffiths DV (eds)). American Society of Civil Engineers, Reston, VA, USA, GSP 283, pp. 384-393, https://doi.org/10.1061/9780784480700.037.

Bjureland W, Spross J, Johansson F, Prästings A and Larsson S (2017b) Reliability aspects of rock tunnel design with the observational method. International Journal of Rock Mechanics and Mining Sciences 98: 102-110, https://doi.org/10.1016/j.ijrmms.2017.07.004.

Cao Z and Wang Y (2014) Bayesian model comparison and characterization of undrained shear strength. Journal of Geotechnical and Geoenvironmental Engineering 140(6): 4014018, https://doi.org/10.1061/\%28ASCE\%29GT.1943-5606.0001108.

Cao Z, Wang Y and Li D (2016) Quantification of prior knowledge in geotechnical site characterization. Engineering Geology 203: 107-116, https://doi.org/10.1016/j.enggeo.2015.08.018.
CEN (European Committee for Standardization) (2002) EN 1990:2002 Eurocode - basis of structural design. CEN, Brussels, Belgium.

CEN (European Committee for Standardization) (2004) EN 1997-1:2004 Eurocode 7: geotechnical design - part 1: general rules. CEN, Brussels, Belgium.

De Koker N and Day P (2018) Assessment of reliability-based design for a spectrum of geotechnical design problems. Proceedings of the Institution of Civil Engineers - Geotechnical Engineering 171(2): 147-159, https://doi.org/10.1680/jgeen.17.00047.

Duncan JM (2000) Factor of safety and reliability in geotechnical engineering. Journal of Geotechnical and Geoenvironmental Engineering 126(4): 307-316, https://doi.org/10.1061/ (ASCE)1090-0241(2000)126:4(307).

Fenton GA and Griffiths DV (2008) Risk Assessment in Geotechnical Engineering. John Wiley \& Sons, Hoboken, NJ, USA, https://doi.org/10.1002/9780470284704.

Fenton GA, Naghibi F and Griffiths DV (2016) On a unified theory for reliability-based geotechnical design. Computers and Geotechnics 78: 110-122, https://doi.org/10.1016/ j.compgeo.2016.04.013.

Forrest WS and Orr TLL (2010) Reliability of shallow foundations designed to Eurocode 7. Georisk: Assessment and Management of Risk for Engineered Systems and Geohazards 4(4): 186-207, https://doi.org/10.1080/17499511003646484.

Frank R, Baudin C, Driscoll R et al. (2004) Designers' Guide to EN 1997-1 Eurocode 7: Geotechnical Design - General Rules. Thomas Telford, London, UK, https://doi.org/10.1680/dgte7.31548.

Honjo Y and Setiawan B (2007) General and local estimation of local average and their application in geotechnical parameter estimations. Georisk: Assessment and Management of Risk for Engineered Systems and Geohazards 1(3): 167-176, https://doi. org/10.1080/17499510701745960.

Honjo Y, Setiawan B and Suzuki M (2006) A statistical method to determine sample size to estimate characteristic value of soil parameters. In Foundation Analysis and Design: Innovative Methods (Parsons P, Zhang L, Guo WD, Phoon KK and Yang M (eds)). American Society of Civil Engineers, Reston, VA, USA, GSP 153, pp. 76-81, https://doi.org/10.1061/40865(197)9.

IEG (Implementation Commission for European Standards in Geotechnics) (2008a) Swedish national annex to Eurocode 7, geotechnical design - part 1: general rules (EN 1997-1). Swedish Geotechnical Society, Stockholm, Sweden.

IEG (Implementation Commission for European Standards in Geotechnics) (2008b) Swedish national annex to Eurocode 7, geotechnical design - part 2: stability of slopes and embankments (6:2008). Swedish Geotechnical Society, Stockholm, Sweden.

Lo SR and Li KSV (2007) Characteristic and design soil parameters: use of statistics. Proceedings of the Institution of Civil Engineers Geotechnical Engineering 160(3): 141-146, https://doi.org/10.1680/ geng.2007.160.3.141.

Lumb P (1974) Application of statistics in soil mechanics. In Soil Mechanics: New Horizons (Lee IK (ed.)). Butterworth, London, UK, pp. 44-111.

Melchers RE and Beck AT (2018) Structural Reliability Analysis and Prediction, 3rd edn. John Wiley \& Sons, Chichester, England.

Müller R, Larsson S and Spross J (2014) Extended multivariate approach for uncertainty reduction in the assessment of undrained shear strength in clays. Canadian Geotechnical Journal 51(3): 231-245, https://doi.org/10.1139/cgj-2012-0176.

Müller R, Larsson S and Spross J (2016) Multivariate stability assessment during staged construction. Canadian Geotechnical Journal 53(4): 603-618, https://doi.org/10.1139/cgj-2015-0037.

Orr TLL (2000) Selection of characteristic values and partial factors in geotechnical designs to Eurocode 7. Computers and Geotechnics 26(3-4): 263-279. 
Orr TLL (2017) Defining and selecting characteristic values of geotechnical parameters for designs to Eurocode 7. Georisk: Assessment and Management of Risk for Engineered Systems and Geohazards 11(1): 103-115, https://doi.org/10.1080/17499518.2016. 1235711.

Orr TLL and Breysse D (2008) Eurocode 7 and reliability-based design. In Reliability-Based Design in Geotechnical Engineering. Computations and Applications (Phoon KK (ed.)). CRC Press, London, UK, pp. 299-344.

Phoon KK (2017a) Role of reliability calculations in geotechnical design. Georisk: Assessment and Management of Risk for Engineered Systems and Geohazards 11(1): 4-21, https://doi.org/ 10.1080/17499518.2016.1265653.

Phoon KK (2017b) Discussion: Some observations on characteristic value. Selection of characteristic value for rock and soil properties using Bayesian statistics and prior knowledge (Wang Y (lead discusser). In Joint TC205/TC304. International Society for Soil Mechanics and Geotechnical Engineering (ISSMGE), London, UK. See https://www.icsmge2017.org/download/19th\% 20ICSMGE_Workshop_TC205\&304.pdf (acessed 09/01/2019).

Phoon KK and Ching J (2013) Can we do better than the constant partial factor design format?. In Modern Geotechnical Design Codes of Practice (Arnold P, Fenton G, Hicks M, Schweckendiek T and Simpson B (eds)). IOS Press, Amsterdam, the Netherlands, pp. 295-310.

Phoon KK and Retief JV (2015) ISO 2394:2015 annex D (reliability of geotechnical structures). Georisk: Assessment and Management of Risk for Engineered Systems and Geohazards 9(3): 125-127, https://doi.org/10.1080/17499518.2015.1077975.

Pohl C (2011) Determination of characteristic soil values by statistical methods. In Proceedings of International Symposium on Geotechnical Safety and Risk, Munich, Germany (Vogt N, Schuppener B, Straub D and Bräu G (eds)). Bundesanstalt für Wasserbau, Karlsruhe, Germany, pp. 427-434.

Prästings A, Spross J, Müller R et al. (2017) Implementing the extended multivariate approach in design with partial factors for a retaining wall in clay. $A S C E-A S M E$ Journal of Risk and Uncertainty in Engineering Systems, Part A: Civil Engineering 3(4): 4017015 , https://doi.org/10.1061/AJRUA6.0000918.

Schneider HR and Schneider MA (2013) Dealing with uncertainty in EC7 with emphasis on the determination of characteristic soil properties. In Modern Geotechnical Design Codes of Practice (Arnold P, Fenton G, Hicks M, Schweckendiek T and Simpson B (eds)). IOS Press, Amsterdam, the Netherlands, pp. 87-101.

Spross J (2016) Toward a Reliability Framework for the Observational Method. PhD thesis, KTH Royal Institute of Technology, Stockholm, Sweden.

Spross J and Johansson F (2017) When is the observational method in geotechnical engineering favourable?. Structural Safety 66: 17-26, https://doi.org/10.1016/j.strusafe.2017.01.006.

Spross J, Olsson L and Stille H (2018a) The Swedish geotechnical society's methodology for risk management: a tool for engineers in their everyday work. Georisk: Assessment and Management of Risk for Engineered Systems and Geohazards 12(3): 183-189, https://doi.org/10.1080/17499518.2017.1416643.

Spross J, Stille H, Johansson F and Palmström A (2018b) On the need for a risk-based framework in Eurocode 7 to facilitate design of underground openings in rock. Rock Mechanics and Rock Engineering 51(8): 2427-2431, https://doi.org/10.1007/ s00603-018-1463-8.

Tang WH (1980) Bayesian frequency analysis. Journal of the Hydraulics Division 106(7): 1203-1218.

Thoft-Christensen P and Baker MJ (1982) Structural Reliability Theory and Its Applications. Springer, Berlin, Germany.

Vanmarcke EH (1977) Probabilistic modeling of soil profiles. Journal of the Geotechnical Engineering Division 103(11): 1227-1246.
Vanmarcke EH (2010) Random Fields: Analysis and Synthesis, 2nd edn. World Scientific, Hackensack, NJ, USA.

Vardanega P and Bolton M (2016) Design of geostructural systems. ASCE-ASME Journal of Risk and Uncertainty in Engineering Systems, Part A: Civil Engineering 2(1): 04015017.

Vick SG (2002) Degrees of Belief: Subjective Probability and Engineering Judgment. ASCE Press, Reston, VA, USA.

Wagenmakers EJ, Lee M, Lodewyckx T and Iverson GJ (2008) Bayesian versus frequentist inference. In Bayesian Evaluation of Informative Hypotheses (Hoijtink H, Klugkist I and Boelen PA (eds)). Springer, New York, NY, USA, pp. 181-207, https://doi.org/ 10.1007/978-0-387-09612-4.

Wakefield J (2013) Bayesian and Frequentist Regression Methods. Springer, New York, NY, USA.

Wang Y (2017) Selection of characteristic value for rock and soil properties using Bayesian statistics and prior knowledge. In Joint TC205/TC304. International Society for Soil Mechanics and Geotechnical Engineering (ISSMGE), London, UK. See https://www.icsmge2017.org/download/19th\%20ICSMGE_ Workshop_TC205\&304.pdf (accessed 09/01/2019).

Wang JP and Xu Y (2015) Estimating the standard deviation of soil properties with limited samples through the Bayesian approach Bulletin of Engineering Geology and the Environment 74(1): 271-278, https://doi.org/10.1007/s10064-014-0609-5.

Yang W, Xu Y and Wang JP (2017) Characterising soil property in an area with limited measurement: a Bayesian approach. Georisk: Assessment and Management of Risk for Engineered Systems and Geohazards 11(2): 189-196, https://doi.org/10.1080/ 17499518.2016.1208828.

Zhang L, Tang HT, Zhang L and Zheng J (2004) Reducing uncertainty of prediction from empirical correlations. Journal of Geotechnical and Geoenvironmental Engineering 130(5): 526-534, https://doi.org/ 10.1061/(ASCE)1090-0241(2004)130:5(526)

\section{How can you contribute?}

To discuss this paper, please email up to 500 words to the editor at journals@ice.org.uk. Your contribution will be forwarded to the author(s) for a reply and, if considered appropriate by the editorial board, it will be published as discussion in a future issue of the journal.

Proceedings journals rely entirely on contributions from the civil engineering profession (and allied disciplines). Information about how to submit your paper online is available at www.icevirtuallibrary.com/page/authors, where you will also find detailed author guidelines. 